\title{
The Armeo Spring as training tool to improve upper limb functionality in multiple sclerosis: a pilot study
}

Domien Gijbels ${ }^{1,2^{*}}$, Ilse Lamers $^{1,2+}$, Lore Kerkhofs ${ }^{3 \dagger}$, Geert Alders ${ }^{1 \dagger}$, Els Knippenberg ${ }^{1 \dagger}$, Peter Feys ${ }^{1,2+}$

\begin{abstract}
Background: Few research in multiple sclerosis (MS) has focused on physical rehabilitation of upper limb dysfunction, though the latter strongly influences independent performance of activities of daily living. Upper limb rehabilitation technology could hold promise for complementing traditional MS therapy. Consequently, this pilot study aimed to examine the feasibility of an 8-week mechanical-assisted training program for improving upper limb muscle strength and functional capacity in MS patients with evident paresis.

Methods: A case series was applied, with provision of a training program (3x/week, 30 minutes/session), supplementary on the customary maintaining care, by employing a gravity-supporting exoskeleton apparatus (Armeo Spring). Ten high-level disability MS patients (Expanded Disability Status Scale 7.0-8.5) actively performed task-oriented movements in a virtual real-life-like learning environment with the affected upper limb. Tests were administered before and after training, and at 2-month follow-up. Muscle strength was determined through the Motricity Index and Jamar hand-held dynamometer. Functional capacity was assessed using the TEMPA, Action Research Arm Test (ARAT) and 9-Hole Peg Test (9HPT).

Results: Muscle strength did not change significantly. Significant gains were particularly found in functional capacity tests. After training completion, TEMPA scores improved $(p=0.02)$, while a trend towards significance was found for the 9HPT $(p=0.05)$. At follow-up, the TEMPA as well as ARAT showed greater improvement relative to baseline than after the 8 -week intervention period ( $p=0.01, p=0.02$ respectively).
\end{abstract}

Conclusions: The results of present pilot study suggest that upper limb functionality of high-level disability MS patients can be positively influenced by means of a technology-enhanced physical rehabilitation program.

\section{Background}

Multiple sclerosis (MS) is a chronic progressive disease of the central nervous system, mainly affecting young adults, leading to cumulative heterogeneous disability over time. Pharmacological therapies are currently able to slow down the inflammatory-related disability progression, but cannot cure the disease nor restore functionality yet [1]. As such, rehabilitation remains necessary to maximize one's functional status. A vast number of studies has now demonstrated beneficial

\footnotetext{
* Correspondence: domien.gijbels@uhasselt.be

† Contributed equally

'REVAL Rehabilitation Research Center, Hasselt University, Agoralaan Building A, BE-3590 Diepenbeek, Belgium

Full list of author information is available at the end of the article
}

effects of physical exercise therapy in MS without stating any important deleterious outcome [2].

The physical exercise interventions in these studies were mostly targeting lower limb function and/or ambulatory mobility $[2,3]$. During the disease course, however, approximately 3 out of 4 MS patients are confronted with upper limb dysfunction, [4] which can manifest bilaterally. As a consequence, a substantial number among them experience a negative impact on important activities of daily living (ADL, e.g. eating or toileting), [5] resulting in dependence and reducing quality of life [6]. Surprisingly, given its relevance, physical rehabilitation studies that specifically target upper limb dysfunction in MS are sparse. By our knowledge, only Mark et al. (2008) have reported, in hemiparetic patients (Expanded Disability Status Scale, EDSS 6.0-7.0; $\mathrm{n}=5$ ),

\section{Biomed Central}


significantly improved real-world upper limb use through constraint-induced movement therapy (CIMT) [7]. Obviously, more research is needed to identify the most optimal treatment methodology as well as the treatment potential for different levels of upper limb dysfunction in MS.

In the last decade, computerized robotic and (electro) mechanical devices have been introduced to provide autonomous, high-intensive training for the upper limb [8]. Such devices could hold promise for complementing traditional MS therapy, as therapy time dedicated to arm and hand function training is often limited, principally being indicated in highly disabled MS patients who have a multiplicity of symptoms requiring treatment. On the other hand, training duration and training intensity are known to be key factors for a successful neurological rehabilitation [9]. In particular, this emerging technology enables independent and repetitive movement practice, and this in a motivating, enriched and interactive virtual learning environment in which complex motor tasks, involving central neural pathways related to proprioceptive and visual feedback processing, need to be accomplished. That way, massed exercise according to principles of motor learning, [10] something that is aimed for in rehabilitation, [11] can be established, also by more severely affected individuals who are unable to sufficiently lift their arm against gravity or lacking minimal fine motor capacity to manipulate objects in daily life setting (cf. CIMT).

In stroke, the use of these devices is already wellestablished. Systematic reviews demonstrated significant improvements in (proximal) upper limb motor strength (Motricity Index, MI) and motor function (Brunnstrom Fugl-Meyer, FM) after robotic/(electro)mechanicalassisted training; however, gains on the ADL level were debatable or modest at best $[8,12]$. Recently, a study in chronic stroke patients implemented repetitive performance of task-oriented movements in a virtual learning environment through means of the gravity-supporting Therapy Wilmington Robotic Exoskeleton (T-WREX) [13]. Significantly improved patient-rated Motor Activity Log (MAL) scores were stated, representing a better quality and higher amount of affected upper limb use for ADL in the home situation.

In MS literature, so far, robotic/(electro)mechanical technology for the upper limb has barely been engaged as a training tool, certainly not with focus to functional capacity outcome. Two studies have reported the usefulness of end-effector robots as assessment tools for quantifying motor coordination in (a)symptomatic MS patients during the execution of robotic tasks (e.g. reaching tasks towards virtual targets on a screen) $[14,15]$. Two other studies have investigated the feasibility of an end-effector robot-based rehabilitation protocol for improving upper limb motor coordination, overall reporting, in moderately affected MS patients (EDSS $3.0-6.5 ; \mathrm{n}=7$ ) who predominantly suffered from ataxia and/or tremor, significant gains in their velocity, linearity and smoothness of reaching movements after 8 training sessions over 2 and 4 weeks respectively $[16,17]$. This was clinically accompanied with a decrease in ataxia and tremor scores and a significant positive result on time scores of the 9-Hole Peg Test (9HPT). The long-term application of technology for rehabilitating upper limb dysfunction due to paresis has not yet been documented.

Therefore, this pilot study aimed to determine the feasibility of an 8-week mechanical-assisted training program for improving upper limb muscle strength and functional capacity in MS patients with paresis. The training program was given supplementary on customary maintaining care by employing the Armeo Spring (Hocoma AG, Zurich, $\mathrm{CH}$ ), a gravity-supporting exoskeleton apparatus.

\section{Methods \\ Participants}

A convenience sample was recruited among MS patients scheduled at the Rehabilitation \& MS Center Overpelt, Belgium. Local neurologists enrolled 10 eligible subjects in present pilot study, which was approved by the appropriate ethical committees. Subjects fulfilled the following inclusion criteria: a definite diagnosis of MS according to the McDonald criteria, [18] and upper limb dysfunction due to evident paresis (characterized by an upper limb MI score $\geq 50$ and $\leq 84)$ [19]. Exclusion criteria were: manifest spasticity (Modified Ashworth Scale $>1$ ) [20] or tremor (Fahn's Tremor Rating Scale > 1) [21] in the upper limb, severe cognitive (Mini-Mental State Examination < 24) [22] or visual (Snellen Test < $50 \%$ ) [23] deficits interfering with the comprehension or execution of presented virtual reality tasks, or another diagnosis (e.g. orthopaedic) having a major effect on upper limb function. Admitted participants had a high level of general disability and were each wheelchairbound, as described by an EDSS 7.0-8.5 [24]. They all gave written informed consent.

\section{Apparatus}

The Armeo Spring (http://www.hocoma.com/en/ products/armeo/armeo-spring/; see also Figure 1), a commercially available replica of the T-WREX, [25] was utilized to train the affected upper limb, being the selfreported dominant side in 8 out of 10 subjects. It is a 5 degree-of-freedom (3 in the shoulder, 1 in the elbow, 1 in the forearm) orthosis without robotic actuators, a socalled passive system. The adjustable mechanical arm allows variable levels of gravity support by means of a 


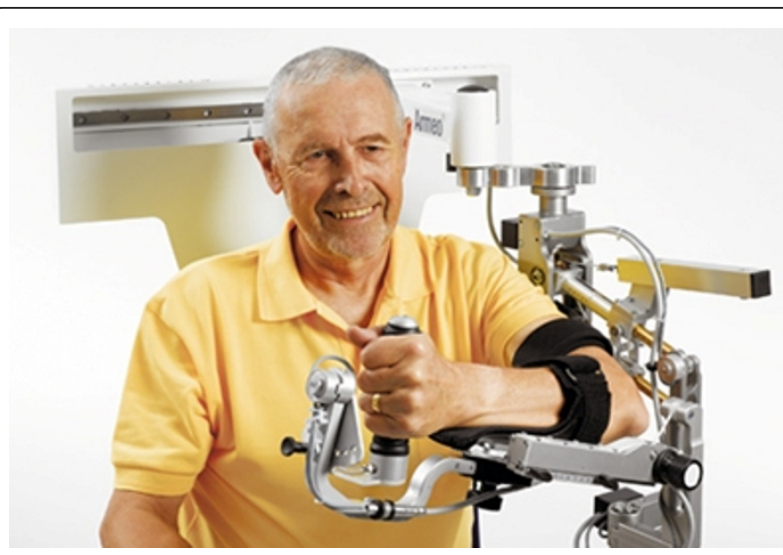

Figure 1 The Armeo Spring, an exoskeleton apparatus with integrated spring mechanism allowing variable upper limb gravity support. Photograph courtesy of Hocoma AG.

spring mechanism. This enables patients, using residual upper limb function, to achieve a larger active range of motion (ROM) within a 3-dimensional workspace than is possible without support [26]. The integration of a pressure-sensitive handgrip additionally allows the execution of graded grasp and release exercises. Through instrumentation of built-in position sensors and software, the Armeo Spring can be engaged as an input device for the accomplishment of meaningful functional tasks (e.g. cleaning a stove top) that are simulated in a virtual learning environment on a computer screen, with the provision of auditory and visual performance feedback during and after practice.

\section{Experimental design, procedure and training program}

An explorative before-after single group research design was applied to examine the feasibility, that is to say the proof of principle, of the training intervention.

An experienced and independent occupational therapist performed the individual setup of the Armeo Spring before training (i.e. establishment of weight compensation, maximal active workspace, and level of exercise difficulty), as well as intermittent supervision under training. The initial amount of gravity support provided by the Armeo Spring was defined based on the subject's ability to maintain the affected arm in a standardized position of $45^{\circ}$ shoulder flexion and $90^{\circ}$ elbow flexion. Setup features were gradually adjusted at the first training session of each week. If as a consequence increased compensatory movements were observed during task execution, former settings were resumed.

Training frequency was 3 times per week for 8 weeks, or 9 weeks in case the participant missed a training session. One session lasted 30 minutes and consisted of intense repetitive performance of 5 out of 15 virtual reality tasks ( 5 minutes per task, ranging from gross motor movement when cleaning a stove top, over more precise movement when watering flowers, to subtle strengthdosed movement when picking up an egg), added with 1 patient-preferred therapy game (e.g. car racing or card playing). The mechanical-assisted training was given supplementary on customary care comprising physical and/or occupational therapy aimed at the maintenance of general functional status (e.g. mobilisations to prevent muscle contractures, respiratory exercises, practise of transfers, etc.; 2 to $3 \times /$ week, 30 minutes/session).

\section{Outcome measures}

Tests were administered by a single independent researcher, a physiotherapist, before and after 24 training sessions as well as 2 months after training completion.

Upper limb and handgrip muscle strength were determined by means of the MI (normal score $=100$ ) and the Jamar hand-held dynamometer (Biometrics Ltd., Ladysmith, USA). Upper limb functional capacity was assessed with the TEMPA, [27] the Action Research Arm Test (ARAT; normal score $=57$ ) [28] and the 9HPT [29]. For the TEMPA, the median execution time of the 4 unilateral activities (i.e. grasping and moving a jar, pouring water from a jug into a cup, inserting coins in a slot, pinching and moving small objects) was registered. The maximal time limit for each of the 4 TEMPA tasks was 120 seconds, while that of the 9HPT was standardized to 300 seconds. Thus, when a patient was not able to finish a TEMPA task or the 9HPT within the specified time frame, a truncated score of respectively 120 and 300 seconds was given.

Also, after completing the 8-week training program, participants rated their global impression of change in upper limb function compared to the perceived state before the intervention. The utilized 7-point ordinal scale (ranging from 1 = very much improved to $7=$ very much worse) was based on the Clinical Global Impression's subscale questioning Change (CGIC) [30].

\section{Statistical analyses}

Normality of the variables was tested applying the Kolmogorov-Smirnov test. Because assumptions of normality were not always fulfilled, and because of the modest sample size, the non-parametric Wilcoxon signed-rank test was implemented to appraise changes in outcome measures after 24 training sessions and at 2-month follow-up relative to baseline. All analyses were done using Statistica (Statsoft Inc., Tulsa, USA). The level of significance was set as $p<0.05$.

\section{Results}

\section{Patient compliance and characteristics}

One patient dropped out during the study due to personal reasons unrelated to the intervention. This subject 
Table 1 Patient characteristics $(\mathbf{n}=9)$

\begin{tabular}{lc}
\hline Variable & \\
\hline Gender $(\mathrm{m} / \mathrm{f})$ & $4 / 5$ \\
Age (years) & $63 \pm 10$ \\
Disease duration (years) & $27 \pm 10$ \\
Type of MS (RR/SP/PP) & $0 / 6 / 3$ \\
EDSS & $7.9 \pm 0.5$ \\
Trained upper limb (D/ND)* & $6 / 3$ \\
\hline
\end{tabular}

Values are mean \pm standard deviation, or number.

$\mathrm{RR}$, relapsing remitting; $\mathrm{SP}$, secondary progressive; $\mathrm{PP}$, primary progressive; EDSS, Expanded Disability Status Scale; D, dominant; ND, non-dominant.

*2 out of 3 non-dominant limbs have become dominant limbs over time because of paralysis of the initial dominant limb.

was excluded from all analyses. Detailed descriptive characteristics of the participants that completed the training program $(n=9)$ are presented in Table 1 . Each of them concluded all 24 training sessions within maximal 9 weeks.

\section{Effects of the Armeo Spring training program on upper limb muscle strength and functional capacity}

Baseline values of the outcome measures and changes over time are provided in Table 2. Armeo Spring training yielded no significant alteration in upper limb muscle strength, although the mean MI score improved subsequent to the intervention, sustaining gain at follow-up. Hand grip force measured with the Jamar remained stable throughout the whole study.

Significant improvements were particularly found in functional capacity parameters (see Figure 2). At completion of the training program, the functional activities of the TEMPA were performed significantly faster compared to baseline, while time scores on the 9HPT gave evidence of a positive trend. ARAT scores increased 4 points on average, not being significant however. Largest gains were observed in subjects most affected at baseline, more specifically in 4 individuals who initially required a TEMPA execution time of more than 60 seconds (see Figure 3 in illustration of this finding) and a 9HPT execution time of more than 180 seconds, besides scoring less than 41 points on the ARAT. In fact, these 4 subjects were not able to accomplish one or more TEMPA tasks (all 4 individuals) or the 9HPT (2 out of 4 individuals) within the specified maximal time frame before the intervention, while most of them were capable after the intervention (3 out of 4 , and 4 out 4 individuals respectively). At 2-month follow-up, results on the TEMPA and ARAT revealed even greater and for both measures significant gains relative to baseline than immediately after the intervention period, despite the fact that in the meantime no supplementary mechanical-assisted training had taken place. The 9HPT outcomes approximated the post-training performance levels.

After finishing the training program, 3 participants rated themselves much improved, 2 participants rated themselves moderately improved, and 4 participants noted no change on the CGIC, without stating any side effects. Interestingly, the 4 subjects who showed greatest responsiveness on the functional capacity parameters were among those declaring much (3 individuals) and moderate (1 individual) self-perceived improvement.

\section{Discussion}

This pilot study reports on an 8-week technologyenhanced training program for improving upper limb muscle strength and functional capacity in MS patients with paresis. The gravity-supporting Armeo Spring was employed as a training tool assisting participants to additionally and independently practice task-oriented movements in a virtual real-life-like learning environment. Importantly, significant gains in the functional capacity outcome measures were found after completion of the intervention period, which sustained or even progressed at 2-month follow-up.

In MS, limited literature is available on rehabilitation of upper limb dysfunction, neither with regard to traditional physical therapy in general, nor with regard to technology-enhanced physical therapy in particular. Previously, a 2 - and 4-week robot-based rehabilitation protocol, applied in moderately affected patients (EDSS 3.5-6.0) who predominantly suffered from cerebellar symptoms like ataxia and/or tremor, led to improved upper limb motor coordination as measured through

Table 2 Changes in outcome measures with Armeo Spring training $(\mathbf{n}=\mathbf{9})$

\begin{tabular}{|c|c|c|c|c|c|}
\hline Variable & $\begin{array}{l}\text { Baseline } \\
\text { value }\end{array}$ & $\begin{array}{l}\Delta \text { after } 24 \text { training } \\
\text { sessions }\end{array}$ & $\begin{array}{l}\mathrm{p} \text { of } \Delta \text { after } 24 \\
\text { training sessions }\end{array}$ & $\begin{array}{l}\Delta \text { at } 2 \text {-month follow-up, } \\
\text { relative to baseline }\end{array}$ & $\begin{array}{l}\mathrm{p} \text { of } \Delta \text { at 2-month follow-up, } \\
\text { relative to baseline }\end{array}$ \\
\hline $\mathrm{MI}$ & $72 \pm 8$ & $4 \pm 7$ & 0.07 & $6 \pm 9$ & 0.08 \\
\hline Jamar (kg) & $14,3 \pm 9,1$ & $0,2 \pm 4,5$ & 0.51 & $0,0 \pm 5,7$ & 0.67 \\
\hline TEMPA (s) & $56,4 \pm 44,1$ & $-23,6 \pm 27,4$ & $0.02^{*}$ & $-26,8 \pm 27,0$ & $0.01^{*}$ \\
\hline ARAT & $45 \pm 13$ & $4 \pm 11$ & 0.31 & $5 \pm 7$ & $0.02^{*}$ \\
\hline 9HPT (s) & $157,1 \pm 114,6$ & $-47,8 \pm 59,4$ & $0.05+$ & $-47,0 \pm 76,9$ & 0.09 \\
\hline
\end{tabular}

Values or mean \pm standard deviation.

$\Delta$ stands for change in outcome measures; ${ }^{*} p<0.05 ;{ }^{+}$trend towards significance.

MI, Motricity Index; ARAT, Action Research Arm Test; 9HPT, 9-Hole Peg Test. 


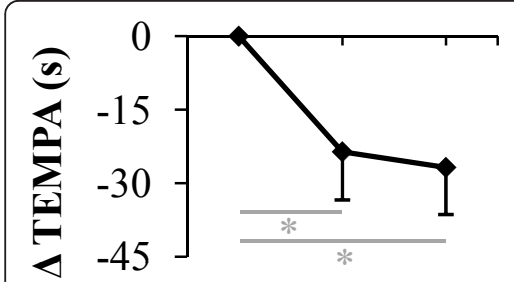

PRE POST FU

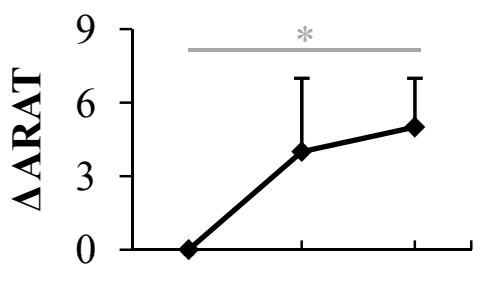

PRE POST FU

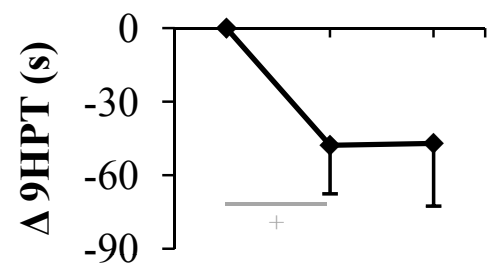

PRE POST FU

Figure 2 Effects of Armeo Spring training on upper limb functional capacity parameters. Changes in outcome measures ( $\triangle$ ) were measured after 8 weeks of training (POST) and at 2-month follow-up (FU), relative to baseline (PRE). Vertical bars show 1 standard error; ${ }^{*} p<$ $0.05 ;{ }^{+}$trend towards significance. ARAT, Action Research Arm Test; 9HPT, 9-Hole Peg Test.

robotic parameters, ataxia and tremor indices, and the 9HPT [16,17]. Current investigation implemented mechanical-assisted training over a longer period of 8 weeks as a treatment modality supplementary on customary maintaining care. Beneficial effects were noted, particularly on the functional capacity level, and this mainly in subjects whose upper limb function was most affected at baseline (i.e. initially having a TEMPA execution time $>60$ seconds, 9 HPT execution time $>180 \mathrm{sec}-$ onds, ARAT score $<41$ points). It were also these individuals that, examined by the CGIC after finishing the training program, perceived at least moderate improvements in their upper limb function compared to the status before the intervention. Patient's quotations were: 'Combing my hair goes easier', 'I can scratch my nose again when it itches', or 'I'm better able to hold a book and turn pages'. Given that precarious arm and hand dysfunction often occurs in a later stage of MS, it is noteworthy that the above findings were obtained in high-level disability patients with an $\operatorname{EDDS} \geq 7$, a patient subgroup that as far as we know has not been studied before in the context of (technology-enhanced) physical rehabilitation [2]. Our study results suggest that the upper limb of such persons, who are already wheelchairbound, is still trainable with profits being established in a functionally relevant way.

It is acknowledged that MS and stroke can present themselves with different clinical symptoms. Nonetheless,

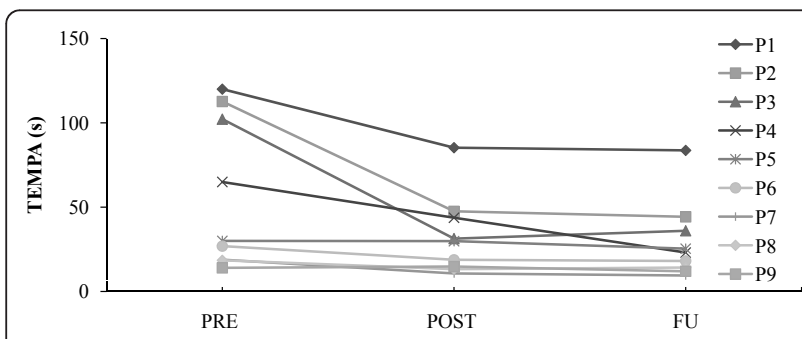

Figure 3 Case profiles of time performance on the TEMPA. Outcomes were measured at baseline (PRE), after 8 weeks of Armeo Spring training (POST), and at 2-month follow-up (FU). P, patient. it is supportive to notice that the reported effects of Armeo Spring training in MS are in concordance with the outcomes of a recent randomized clinical trial (RCT) in stroke patients with chronic hemiparesis (cf. two distinct pathologies showing similar upper limb dysfunction caused by upper motor neuron lesions) [13]. This RCT also demonstrated, subsequent to 8 weeks of gravity-supported T-WREX training, functionally relevant changes in the use of the affected upper limb in terms of significantly improved patient-rated MAL scores, besides significant gains in active reaching ROM and the FM. In both studies in MS and stroke, handgrip force measured with the Jamar showed no significant alteration. This might be because especially proximal muscles around the shoulder girdle, shoulder and elbow joint were exercised during the execution of virtual reality tasks. The pressure-sensitive handle integrated in the exoskeleton systems effectively allows grasp and release exercises, but these only need to be performed submaximally in part of the tasks. In present research, the MI measuring overall upper limb muscle strength improved, albeit non-significant. A less pronounced gain in strength is not entirely surprising given that the Armeo Spring(/T-WREX) device provides anti-gravity support, notwithstanding the fact that this support had (slightly) decreased in all subjects at the end of the training period.

Movement practice in a virtual environment with the Armeo Spring may rather be considered as dexterity training, by which (partial) relief of the upper limb's weight enables the more severely affected patient to actively produce a larger ROM within a 3-dimensional workspace [31]. Dexterity is hereby defined as the ability to address spatial and temporal accuracy necessary to make the movement meet environmental demands [32]. So mechanical-assisted therapy in a virtual workspace engages not just repeated use of the upper limb, but involves repetitive and active exertion of goal-directed movements, with enlarged ROM and superior multijoint coordination, during the practice of complex motor tasks in an enriched learning environment. Focus on dexterity during (technology-enhanced) task-oriented 
training is deliberately wanted by therapists, [33] and could have been a main driver for the improved functional outcome of the upper limb in both MS and chronic stroke patients [11].

The improved functional capacity is of importance as systematic reviews assessing the effectiveness of robotic/ (electro)mechanical-assisted training in stroke mainly demonstrated significant gains in upper limb motor function, contrary to benefits on the ADL level which were less pronounced $[8,12]$. In the selected studies for review, emphasis was rather put on 2-dimensional goaldirected instead of 3-dimensional task-oriented training, which might have contributed to the lack of effectiveness for functional recovery. However, the limited contrast between experimental and control interventions can be another issue in this regard. In the recent RCT of Housman et al. (2009), patients receiving control therapy in the form of conventional table top exercises, positively exhibited similar improvements on the outcome measures as patients receiving mechanical-assisted training with the T-WREX, except for a modest sustained gain on the FM at 6-month follow-up in favour of T-WREX, while participants expressed their preference for T-WREX training after a single-session crossover treatment [13]. It seems unlikely that robotic/ (electro)mechanical-assisted training will arrive at better results than another training modality/therapistmediated training under the premise that the content, frequency, amount and intensity of therapy are comparable [34]. Yet, rehabilitation technology enables stimulating as well as cost-effective practice, since it can be performed on a relatively autonomous and additional basis, also by a more disabled patient population as the one in the present study that does not necessarily meet the selection criteria for a functional training modality such as CIMT [35].

Another important finding in current investigation is the fact that the noted effects on the functional capacity level sustained or even progressed at 2-month followup. Analogue statements were made in the above mentioned T-WREX study in stroke, where functionally relevant changes revealed by the MAL showed greater significant improvement at 6-month follow-up relative to baseline than after the 8-week intervention period. This patient-reported index supports our assumption that beneficial effects of technology-enhanced training plausibly culminated an increased spontaneous use of MS patients' paretic upper limb in the habitual life situation, retaining or further enhancing outcome over time. It also suggests that 8 weeks of repetitive weightsupported practice in a virtual setting can work out transferred and durable benefits in non-weightsupported real-world upper limb functionality in either chronically affected MS and stroke patients. Within this context, it is regretful that the two studies in diverse pathologies applied other outcome measures on the various domains of the International Classification of Functioning, Disability and Health (ICF), [36] hindering direct comparison of the extent of improvement between neurological conditions and possible differential effects of different total training times in both investigations. Future research in MS should therefore consider the inclusion of parameters that are frequently used in stroke, such as the MAL (although not yet fairly applicable in MS as it compares the affected with the nonaffected upper limb, whereas motor symptoms can manifest bilaterally in MS patients) and the FM index $[37,38]$.

Present study is not without limitations, while the underlying mechanisms for changes in motor performance are not fully clear. Firstly, this pilot investigation applied a before-after single group research design in a limited sample size without incorporation of a control group, given that the aim of the study was to ascertain proof of principle and treatment potential of mechanical-assisted upper limb training in MS patients with paresis. Nevertheless, it is believed that the reported changes in upper limb functionality reflect true improvement rather than a practice effect related to repeated test execution, since one would not expect to perceive substantial gains in chronically and severely disabled MS patients (EDSS $\geq 7$ ) [39]. Besides, the participants were familiar with the outcome measures as these are part of the routine clinical assessment administered at the Rehabilitation and MS Center Overpelt. Secondly, in retrospect, implementation of a parameter on the ICF's participation level examining upper limb use in the daily life, such as the subjective MAL or an objective wrist actigraph like proposed by Kos et al. (2007), [40] would have made this research more solid. Those instruments are closer to demonstrate the ultimate rehabilitation objective, which is having a positive impact on the community function of patients. Also, the included functional capacity outcome measures do not allow explanation about the underlying mechanisms on the basis of improved motor performance. Neural plasticity has already been shown in MS, conceivably moderating the clinical manifestations of the disease [41]. Given that the applied practice modality in present investigation implemented adaptive motor learning, [42] one could question oneself if this may have led to the stimulation of restorative brain plasticity resulting in genuine upper limb motor recovery. On the other hand, the functional gain could also be owing to the usage of more efficient compensation strategies (e.g. enhanced trunk and proximal arm movement) or, very realistically, the overcoming of learned non-use secondary to MS. Future research should regard the application of both 
kinematical (e.g. accelerometry) and neurophysiological (e.g. transcranial magnetic stimulation) measurements to determine quality of movement and to comprehend the neural substrates underlying motor performance.

\section{Conclusions}

This pilot study is the first one to provide indications that technology-enhanced physical rehabilitation is effective for improving upper limb functionality in high-level disability MS patients with paresis, and this in a durable manner. Beneficial effects were mainly noted in individuals most affected at baseline. Further RCTs including a broader assessment are warranted to confirm and elaborate these results.

\section{Consent}

Written informed consent was obtained for publication of the accompanying image. A copy of the written consent is available for review by the Editor-in-Chief of this journal.

\section{Acknowledgements}

Domien Gijbels is recipient of a PhD fellowship from the Research Foundation Flanders (FWO), while the other authors are involved in the European Interreg IV project 'Rehabilitation Robotics II' (IVA-VLANED-1.14). The authors thank Erik De Winter (Enraf-Nonius, local distributor for Hocoma AG in Belgium) for lending the Armeo Spring apparatus, Dr Bart Vanwijmeersch for patient recruitment, and Herbert Thijs for his contribution in data processing. The Belgian Charcot Foundation is acknowledged for their Equipment Grant (2008), the FWO for their Research Grant ('Krediet aan Navorsers') to Peter Feys.

\section{Author details}

'REVAL Rehabilitation Research Center, Hasselt University, Agoralaan Building A, BE-3590 Diepenbeek, Belgium. ${ }^{2}$ BIOMED Biomedical Research Institute, Hasselt University, Agoralaan Building A, BE-3590 Diepenbeek, Belgium. ${ }^{3}$ RMSC Rehabilitation \& MS Center, Boemerangstraat 2, BE-3900 Overpelt, Belgium.

\section{Authors' contributions}

DG and PF conceived of the study, participated in its design and coordination, and drafted the manuscript. IL, GA and EK co-operated in the study design and performed data collection. DG and PF carried out the statistical analysis. LK provided project management and consultation. All authors read and approved the final manuscript.

\section{Competing interests}

The authors declare that they have no competing interests.

Received: 19 August 2010 Accepted: 24 January 2011

Published: 24 January 2011

\section{References}

1. Pittock SJ, Lucchinetti CF: The pathology of MS: new insights and potential clinical applications. Neurologist 2007, 13:45-56.

2. Dalgas U, Stenager E, Ingemann-Hansen T: Multiple sclerosis and physical exercise: recommendations for the application of resistance-, enduranceand combined training. Mult Scler 2008, 14:35-53.

3. Snook EM, Motl RW: Effect of exercise training on walking mobility in multiple sclerosis: a meta-analysis. Neurorehabil Neural Repair 2009, 23:108-116.

4. Johansson S, Ytterberg C, Claesson IM, Lindberg J, Hillert J, Andersson M, Widén Holmqvist L, von Koch L: High concurrent presence of disability in multiple sclerosis. Associations with perceived health. J Neurol 2007, 254:767-773.

5. Paltamaa J, Sarasoja T, Leskinen E, Wikstrom J, Malkia E: Measures of physical functioning predict self-reported performance in self-care, mobility, and domestic life in ambulatory persons with multiple sclerosis. Arch Phys Med Rehabil 2007, 88:1649-1657.

6. Yozbatiran N, Baskurt F, Baskurt Z, Ozakbas S, Idiman E: Motor assessment of upper extremity function and its relation with fatigue, cognitive function and quality of life in multiple sclerosis patients. J Neurol Sci 2006, 246:117-122.

7. Mark WW, Taub E, Bashir K, Uswatte G, Delgado A, Bowman MH, Bryson CC, McKay S, Cutter GR: Constraint-Induced Movement therapy can improve hemiparetic progressive multiple sclerosis. Preliminary findings. Mult Scler 2008, 14:992-994.

8. Kwakkel G, Kollen BJ, Krebs HI: Effects of robot-assisted therapy on upper limb recovery after stroke: a systematic review. Neurorehabil Neural Repair 2008, 22:111-121.

9. Kwakkel G, van Peppen R, Wagenaar RC, Wood DS, Richards C, Ashburn A, Miller K, Lincoln N, Partridge C, Wellwood I, Langhorne P: Effects of augmented exercise therapy time after stroke: a meta-analysis. Stroke 2004, 35:2529-2539.

10. Magill R: Motor Learning and Control, Concepts and Applications New York, NY: The McGraw-Hill Companies; 2007.

11. Van Peppen RP, Kwakkel G, Wood-Dauphinee S, Hendriks HJ, Van der Wees PJ, Dekker J: The impact of physical therapy on functional outcomes after stroke: what's the evidence. Clin Rehabil 2004, 18:833-862.

12. Mehrholz J, Platz T, Kugler J, Pohl M: Electromechanical and robot-assisted arm training for improving arm function and activities of daily living after stroke. Cochrane Database Syst Rev 2008, CD006876.

13. Housman SJ, Scott KM, Reinkensmeyer DJ: A randomized controlled trial of gravity-supported, computer-enhanced arm exercise for individuals with severe hemiparesis. Neurorehabil Neural Repair 2009, 23:505-514.

14. Casadio M, Sanguineti V, Morasso P, Solaro C: Abnormal sensorimotor control, but intact force field adaptation, in multiple sclerosis subjects with no clinical disability. Mult Scler 2008, 14:330-342.

15. Feys P, Alders G, Gijbels D, De Boeck T, De Weyer T, Coninx K, Raymaekers C, Truyens V, Groenen P, Meijer K, Savelberg H, Eijnde BO: Arm training in multiple sclerosis using Phantom: clinical relevance of robotic outcome measures. Proceedings of the 11th International Conference of the IEEE Rehabilitation Robotics, Kyoto 2009, 576-581.

16. Carpinella I, Cattaneo D, Abuarqub S, Ferrarin M: Robot-based rehabilitation of the upper limbs in multiple sclerosis: feasibility and preliminary results. J Rehabil Med 2009, 41:966-970.

17. Vergaro E, Squeri V, Brichetto G, Casadio M, Morasso P, Solaro C, Sanguineti V: Adaptive robot training for the treatment of incoordination in Multiple Sclerosis. J Neuroeng Rehabil 2010, 7:37.

18. McDonald WI, Compston A, Edan G, Goodkin D, Hartung HP, Lublin FD, McFarland HF, Paty DW, Polman CH, Reingold SC, Sandberg-Wollheim M, Sibley W, Thompson A, van den Noort S, Weinshenker BY, Wolinsky JS: Recommended diagnostic criteria for multiple sclerosis: guidelines from the International Panel on the diagnosis of multiple sclerosis. Ann Neurol 2001, 50:121-127.

19. Collin C, Wade D: Assessing motor impairment after stroke: a pilot reliability study. J Neurol Neurosurg Psychiatry 1990, 53:576-579.

20. Bohannon RW, Smith MB: Interrater reliability of a modified Ashworth scale of muscle spasticity. Phys Ther 1987, 67:206-207.

21. Hooper J, Taylor R, Pentland B, Whittle IR: Rater reliability of Fahn's tremor rating scale in patients with multiple sclerosis. Arch Phys Med Rehabil 1998, 79:1076-1079.

22. Pfeiffer E: A short portable mental status questionnaire for the assessment of organic brain deficit in elderly patients. J Am Geriatr Soc 1975, 23:433-441.

23. Hetherington R: The Snellen chart as a test of visual acuity. Psychol Forsch 1954, 24:349-357.

24. Kurtzke JF: Rating neurologic impairment in multiple sclerosis: an expanded disability status scale (EDSS). Neurology 1983, 33:1444-1452.

25. Sanchez RJ, Reinkensmeyer D, Shah P, Liu J, Rao S, Smith R, Cramer S, Rahman T, Bobrow J: Monitoring functional arm movement for homebased therapy after stroke. Proceedings of the 26th International Conference of the IEEE Engineering in Medicine and Biology Society San Francisco, CA; 2004, 4787-4790. 
26. Sanchez RJ, Liu J, Rao S, Shah P, Smith R, Rahman T, Cramer SC, Bobrow JE, Reinkensmeyer DJ: Automating arm movement training following severe stroke: functional exercises with quantitative feedback in a gravityreduced environment. IEEE Trans Neural Syst Rehabil Eng 2006, 14:378-389.

27. Feys $P$, Duportail M, Kos D, Van AP, Ketelaer P: Validity of the TEMPA for the measurement of upper limb function in multiple sclerosis. Clin Rehabil 2002, 16:166-173.

28. Lyle RC: A performance test for assessment of upper limb function in physical rehabilitation treatment and research. Int J Rehabil Res 1981, 4:483-492.

29. Fischer JS, Rudick RA, Cutter GR, Reingold SC: The Multiple Sclerosis Functional Composite Measure (MSFC): an integrated approach to MS clinical outcome assessment. National MS Society Clinical Outcomes Assessment Task Force. Mult Scler 1999, 5:244-250.

30. Guy W: ECDEU Assessment Manual for Psychopharmacology Rockville, MD: US Department of Health, Education and Welfare Public Health Service Alcohol, Drug Abuse, and Mental Health Administration; 1976.

31. Beer RF, Ellis MD, Holubar BG, Dewald JP: Impact of gravity loading on post-stroke reaching and its relationship to weakness. Muscle Nerve 2007, 36:242-250.

32. Ada L, Canning C: Changing the way we view the contribution of motor impairments to physical disability after stroke. In Science-based Rehabilitation, Theories into Practice. Edited by: Refshauge K, Ada L, Ellis E. Sydney: Butterworth-Heinemann; 2005:87-106.

33. Timmermans AA, Seelen HA, Willmann RD, Kingma H: Technology-assisted training of arm-hand skills in stroke: concepts on reacquisition of motor control and therapist guidelines for rehabilitation technology design. J Neuroeng Rehabil 2009, 6:1.

34. Volpe BT, Lynch D, Rykman-Berland A, Ferraro M, Galgano M, Hogan N, Krebs HI: Intensive sensorimotor arm training mediated by therapist or robot improves hemiparesis in patients with chronic stroke. Neurorehabil Neural Repair 2008, 22:305-310.

35. Sirtori V, Corbetta D, Moja L, Gatti R: Constraint-induced movement therapy for upper extremities in stroke patients. Cochrane Database Syst Rev 2009, CD004433.

36. WHO: International Classification of Functioning, Disability and Health: ICF Geneva: World Health Organization; 2001.

37. Timmermans AA, Seelen HA, Willmann RD, Bakx W, de RB, Lanfermann G, Kingma H: Arm and hand skills: training preferences after stroke. Disabil Rehabil 2009, 31:1344-1352.

38. Gladstone DJ, Danells CJ, Black SE: The fugl-meyer assessment of motor recovery after stroke: a critical review of its measurement properties. Neurorehabil Neural Repair 2002, 16:232-240.

39. Ytterberg $C$, Johansson $S$, Andersson M, Widén Holmqvist $L$, von Koch $L$ : Variations in functioning and disability in multiple sclerosis. A two-year prospective study. J Neurol 2008, 255:967-973.

40. Kos D, Nagels G, D'Hooghe MB, Duquet W, Ilsbroukx S, Delbeke S, Kerckhofs E: Measuring activity patterns using actigraphy in multiple sclerosis. Chronobiol Int 2007, 24:345-356.

41. Rocca MA, Pagani E, Absinta M, Valsasina P, Falini A, Scotti G, Comi G, Filippi M: Altered functional and structural connectivities in patients with MS: a 3-T study. Neurology 2007, 69:2136-2145.

42. Adamovich SV, Fluet GG, Tunik E, Merians AS: Sensorimotor training in virtual reality: a review. NeuroRehabilitation 2009, 25:29-44.

\section{Submit your next manuscript to BioMed Central and take full advantage of:}

- Convenient online submission

- Thorough peer review

- No space constraints or color figure charges

- Immediate publication on acceptance

- Inclusion in PubMed, CAS, Scopus and Google Scholar

- Research which is freely available for redistribution

Submit your manuscript at www.biomedcentral.com/submit 